\title{
NATIONAL IMMUNIZATION PROGRAM: VACCINATION, COMPLIANCE AND PHARMACOVIGILANCE
}

\author{
Carla Magda Allan S. DOMINGUES(1,2), Antonia Maria da Silva TEIXEIRA(1) \& Sandra Maria Deotti CARVALHO(1)
}

The vaccine is one of the main control measures available for a major portion of infectious and transmissible diseases. It stands out as one of the great discoveries of public health for the benefit of the population.

In Brazil, more than two centuries have passed since the first time (1804) the vaccine was administered as a control measure to prevent smallpox. Exactly a century later (1904), an epidemic of this disease led the President of the Republic Rodrigues Alves, to establish the obligation of the vaccination. In the same year, the hygienist Osvaldo Cruz coordinated the mass vaccination of the Rio de Janeiro`s population in order to control the epidemic. This movement generated a historical episode known as "The Vaccine Revolt" characterized by population rebellion and rejection to the measure adopted, culminating in the suspension of mandatory vaccination ${ }^{1,2}$.

In this same century (XX), especially in the first half, epidemics of several diseases had been occurring in the country. It was also the moment that began the production and/or introduction of new vaccines in the country, when the first positive results appeared in control of some epidemics, elimination and eradication of diseases. Among the accomplishments of that time includes the introduction of yellow fever vaccine in 1937 with the interruption of urban-form disease transmission five years later (1942); the introduction of diphtheria-tetanus toxoidscellular pertussis vaccine (DTP), tetanus toxoid (TT) in 1950 for the prevention of tetanus, diphtheria and pertussis, diseases considered under control.

Early in the second half of that century poliomyelitis vaccine was introduced with the first mass vaccination campaign conducted in the cities of Petrópolis, state of Rio de Janeiro (RJ) and Santo André, state of São Paulo (SP) in $1961^{1}$ and also monovalent measles vaccine deployed in 1967 and 1968, and that disease is currently in the process of certifying their eradication in the country.

Regarding to smallpox, the last case reported in Brazil occurred in 1971 and the international certification of eradication was granted by the World Health Organization - WHO in 1973. The global eradication stood out as the first major victory for the public health.

During this period, if on the one hand successes were already seen by the use of vaccines for control, elimination and eradication of diseases, on the other hand, the lack or insufficient products to combat other diseases was the subject of pressure in the sector. A remarkable fact was an epidemic of meningococcal meningitis that spread in the country in the mid 70's, the so-called "epidemic under censorship". The insufficient doses of vaccines in the country and of the capacity to import vaccine doses to attend the population, made the current military government to prevent any disclosure of the fact in the media. However, this was only possible while the occurrence of cases did not reach different social strata of the population; when this began to occur, the information reached the media, which generated population pressure on the government ${ }^{3,4}$.

Despite these contrasts, it was in this context that important advances occurred regarding the organization of the structure and actions of immunization in Brazil. In the early 70's (1973) the National Immunization Program (NIP) was created linked to the National Division of Epidemiology and Health Statistics of the Ministry of Health. This aimed to arrange in a single sector immunization activities formerly structured in isolated programs of disease control, especially the vaccination campaign against smallpox and the National Plan for the Control of Poliomyelitis (PNCP). It was regulated by Decree 78.231 of August 1976 and was the first official immunization schedule published in 1977 by Ministerial Decree ${ }^{\circ}$ 452/1977 setting out the mandatory vaccines for children under one year old: tuberculosis, poliomyelitis, measles, diphtheria, tetanus and pertussis.

The 80's were characterized by the creation of the National Institute for Quality Control in Health (INCQS) in 1981, the National Center for Distribution and Storage (Cenade), in Bio-Manguinhos/Fiocruz in 1982 and the National Self-Sufficiency Program in Immunobiologics in 1985. They were intended to garantee the quality of the vaccines offered to the population, to strengthen the capacity of production and self-sufficiency by the national laboratories ${ }^{1,5,6}$.

Another achievement was regarding poliomyelitis. The last case was reported in Brazil in 1989. Factors such as the National Poliomyelitis Control Plan established in 1971, the introduction of the oral poliomyelitis vaccine (OPV) from 1974 and the adoption of mass vaccination national days in 1980, led to the second major victory in the field of immunization. The disease has been certified as eradicated as the circulation of wild viruses in the Americas in 1994 $4^{1,7}$.

Until then, NIP aimed to target primarily the pediatric population. However, with the expansion of the capacity of vaccine's manufacturers, 
the epidemiological surveillance and improvement in vaccination coverages allowed the reduction of vaccine-preventable diseases' incidence; new products have been gradually incorporated into the list of immunobiological products already available. New vaccines were included and new immunization schedules were published boosting the supply of existing vaccines for other target groups in the national schedule.

Still at the end of the last century, in the early years of the 90's, hepatitis B vaccination has been initiated in areas of high endemicity. Than in 1996, new strategies were defined in relation to hepatitis B vaccination. This should target children under one year of age throughout the country and extend to those under 15 years old in the Legal Amazon, Santa Catarina, Espírito Santo and Federal District.

Since 1999, immunization with seasonal influenza vaccine was initiated for the elderly from 65 years of age and, in the following year, was extended to the elderly from 60 years of age. In that same year (1999), the combined diphtheria and tetanus toxoids vaccine (dT) began to compose the national immunization schedule for the population from the age of seven, replacing the tetanus toxoid.

In 2004, Ordinance 457/2004 established rules to the immunization schedules in a life cycle: children; adolescents; adults and elderly subjects, thus demonstrating that the vaccine in the country was already in fact an input available to the whole family. This included definitely in the routine the MMR vaccine (measles, rubella and mumps vaccine) in order to replace the monovalent measles vaccine and was recommended for children completing one year of age, followed by a second dose between four and six years and also included adolescents and adults, subjects not vaccinated in the childhood. It is worth mentioning that the MMR vaccination started in the year 1992 to the year 2000 progressively by the Brazilians states, through campaigns for children between one and 11 years of age.

In 2006, by the Ordinance $1,602 / 2006$ a new vaccine was included, the oral human rotavirus vaccine (RHV) in the schedule for children from six to 24 weeks of age.

In 2008 a national campaign was performed to reach the goal to the elimination of Rubella and the congenital rubella syndrome (CRS), beyond aiming to consolidate the strategy to eliminate measles in the country, targeting the susceptible adult groups.

In 2010, Ordinance 3,318/2010 was published incorporating to the routine pediatric schedule Pneumococcal conjugate 10-valent (PCV10) and Meningococcal C conjugate vaccines, as the goal of the Strategic Plan for Development of the Ministry of Health (PAC Mais Saúde).

The Pandemic Influenza A (H1N1)2009 national immunization campaign performed in 2010, 89.5 million persons, considered the most vulnerable groups to get sick or die from the disease (pregnant women, children between six months and two years old, health workers, indigenous and persons with chronic diseases), were vaccinated and this represented $46.9 \%$ of the total population of the country. In 2011, the influenza vaccine has been extended to these same priority groups.

In this same year, vaccination to hepatitis B was also expanded for people between 20 and 24 years of age, whereas since the mid-2000's this had been extended to children and adolescents up to the age of 19 years across the country.

It is noteworthy that, in general, the introduction of new vaccines in the country is based on epidemiological, economic, safety, efficacy and logistic criteria. Studies of cost-effectiveness are important to help prioritize the deployment of vaccines demonstrating the interest of NIP to make decision based on scientific evidence. Currently, NIP offers 44 different types of immunobiological products, including vaccines and homologous and heterologous sera.

In accordance with the principles of universality and fairness of the Unified Health System (SUS), the Ordinance 1,946/2010 regulates a different schedule for indigenous population that, given the increased vulnerability of this population to disease, get benefits from products not yet routinely available to the general population. Therefore, in 1993 the implementation of the Special Immunobiologicals Reference Centers (CRIES) was initiated. It consists of 42 vaccine rooms that offer immunobiologicals for people with special medical conditions, not available in the routine immunization services; also, these are considered reference centers to manage serious adverse events following immunization (AEFI).

Regarding the history of organizational structure, NIP was bound in different organs in the Ministry of Health, and remains as a strong structure in public health policy of the country with advances in all aspects to fulfill the important mission to vaccinate the population. In 2003, with the creation of the Secretariat of Health Surveillance, this is currently linked to the Department of Transmissible Disease Surveillance occupying the position of General Coordination (Decree 7,530 of July 2011). Under the federal units and cities, it is organized in different structures, usually linked to the area of Health Surveillance. It has a service network consisting of approximately 34,000 vaccine rooms distributed in 5,565 cities. To reach the population, different immunization strategies are used: routine, campaigns, intensification and vaccinal blocking, the latter ones upon outbreak occurrence.

The financing of the actions is among the priorities of Ministry of Health with resources defined in the annual budget, in a separate item for the purchase of immunobiologicals, and for such purpose, not subject to budget cutting, as per Budget Guidelines Law - LDO n ${ }^{\circ} 12,465$ of 12/Aug/2011, section I, $\mathrm{n}^{\circ} 61^{8}$. Considering the period from 1995 to 2010 , the resources spent on the acquisition of immunobiologicals exceed the figure of one billion reais, given the gradual introduction of new vaccines in the national immunization schedule. In 2010 with the expenses with pandemic A influenza (H1N1) 2009 vaccine campaign, this amount exceeded two billions reais (Fig. 1).

Despite all these advances, until the mid-90's, the records of vaccination in the country weren't adequate. At the national level, there were only data consolidated by the states (Federative Units) with no local (city) information. The ever increasing complexity of the program in different areas and in particular on increasing the supply and use of vaccines, the knowledge of vaccination coverage in different management levels, particularly in the city has become increasingly required and also the impact of these on the diseases surveillance.

The first initiatives for a computerized national registry of 


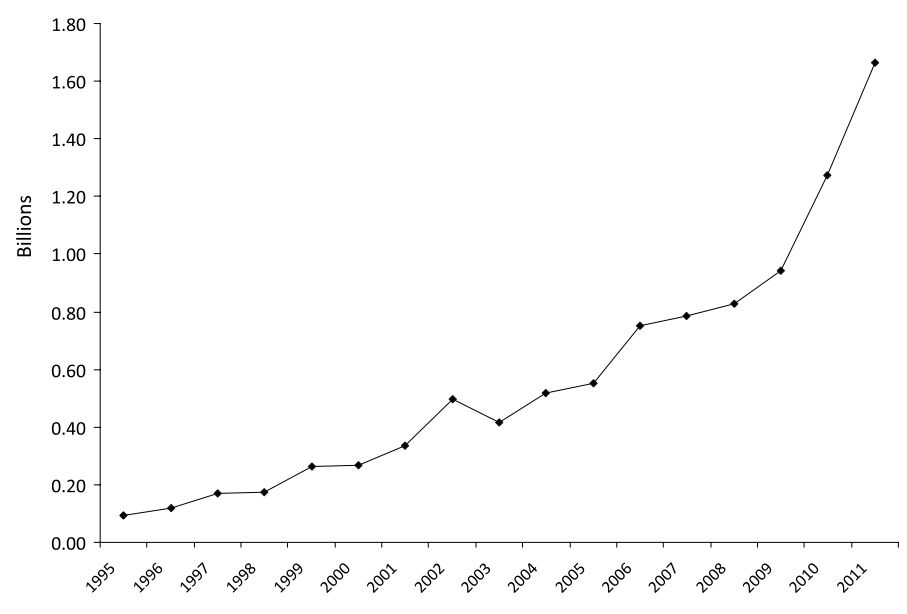

Source: CGPNI/DEVEP/SVS *Not included purchase value of the vaccine influenza A (H1N1) in 2010: about 1.4 billion

Fig.1 -Budget of the National Immunization Program run with the acquisition of biological, Brazil, from 1995 to 2011*.

immunobiological doses applied were from 1994. The Information System of Evaluation of National Immunization Program (SIAPI) was developed in partnership with the Informatics Department of SUS (Datasus). This decentralized system for $100 \%$ of the cities and computerized in about 5,500 of those, makes available immunization data according to immunobiologicals, age group and occurrence of immunization, allowing finding out and monitoring vaccination coverage in the different target groups of immunization. In addition, other systems were created to better provide information about distributed and used doses, physical and technical losses, doses used in the CRIES, monitoring of AEFI, always with NIP assisting in the decision-making.

\section{VACCINATION COVERAGE IN BRAZIL}

The best way or indicator to evaluate the performance of vaccination actions is to analyze the vaccination coverage. The vaccination coverage indicator represents the proportion of target population vaccinated, while the homogeneity of coverage represents the proportion of cities or area within a geographic context that reached the goal set for vaccination coverage ${ }^{8}$.

It is obtained by dividing the number of doses and the target population multiplied by one hundred, and the homogeneity of coverage is obtained by dividing the number of cities which reached appropriate vaccination coverage divided by the total number of cities multiplied by one hundred. The calculation of coverage takes into account the last dose of the recommended schedule for each vaccine.

Both indicators are tools of agreement between all the levels of SUS management (vaccination coverage rates) and they are very important for decision making at the different management levels since adequate coverage, according to the parameters established for each vaccine, are required to obtain control, maintain eliminated and or eradicated vaccinepreventable diseases under surveillance.

The rates established for vaccination coverage are: $90 \%$ for BCG and Rotavirus (VRH); $100 \%$ for yellow fever vaccine in areas with vaccination's recommendation; $95 \%$ for other vaccines in the pediatric schedule and $80 \%$ for influenza vaccine.

At the national and state levels, until the late 80's, routine vaccination coverage did not exceed $70 \%$ of the target population. Those low rates were insufficient to promote impact on diseases ${ }^{1}$. Only from the second half of the 90's coverage reached adequate rates and from those years on, decrease was seen with emphasis on polio and measles (Fig. 2 and 3).

Considering the last ten years, the rates of vaccination coverage for vaccines in the pediatric schedule were high, reaching or surpassing the goals set by PNI. Exceptions are for hepatitis B vaccine, in the first five years of the series, they were below the target (95\%) and for rotavirus vaccine since 2007 (Fig. 4).

Taking as example the vaccination coverage and homogeneity of coverage for vaccine DTP+Hib (tetra) in children under one year old agreed in the SUS intermanagement agreement in 95\% and $70 \%$ respectively, compliance was checked with the goals of coverage throughout the period. With regard to homogeneity, this was reached since 2006 , recording fluctuations in the indicator that ranged from $61.69 \%$ (2005) to $88.86 \%$ (2006) of the 5,565 cities with adequate coverages established of $\geq 95 \%$ (Fig. 4). A similar pattern was found for other vaccines, such as polio and hepatitis B. In relation to MMR vaccine in children of one year old, in the same period, the coverages remained above target of $95 \%$ and homogeneity ranged from $87.23 \%$ (2003) to $69.24 \%$ (2010) of the cities with appropriate coverage.

Vaccination campaigns against poliomyelitis in children under five years of age were successful in the first five years after the implementation in 1980 showing a decrease in both steps within three years of the same decade culminating with recrudescence of cases. From 1989 (last case reported in Brazil) appropriate rates for vaccination coverage were recovered remaining high until the present day (Fig. 2).

In relation to cumulative vaccination coverage of hepatitis B vaccine in children and adolescents from 1994 to June 2011, aged 1 to 24 years, this was $80 \%$ and was inversely proportional to age group, especially in groups one to four years, five to 10 years and 11 to 14 years old, when the rates already exceed $95 \%$ coverage.

Regarding vaccination with seasonal influenza, the target vaccination coverage was originally (1999) set to 70\%, remaining until 2007. In 2008 this was raised to $80 \%$ of the target population. Since 1999 , the country has been showing good compliance of the target population, based on the good results of the coverage. These ranged from $67 \%$ in 2000 , the only year with $\mathrm{VC}<70 \%$, to $85.73 \%$ in 2006 , emphasizing that in the last five years remained above $75 \%$, and in some years this exceeded $80 \%$. The total of doses applied from 1999 on was increasing, consistent with the growth of the target population. The number of doses varied from 7.5 million in 1999 to over 16 million doses in 2011 (Fig. 6).

With respect to immunization campaigns covering young and adult population, the national immunization campaign for elimination of rubella and congenital rubella syndrome and maintenance of measles elimination stood out. In this campaign 67.8 million Brazilians were vaccinated, aged 20 to 39 years throughout the country, adding to the group 12 - 19 years in the states of Maranhão, Minas Gerais, Mato Grosso, 


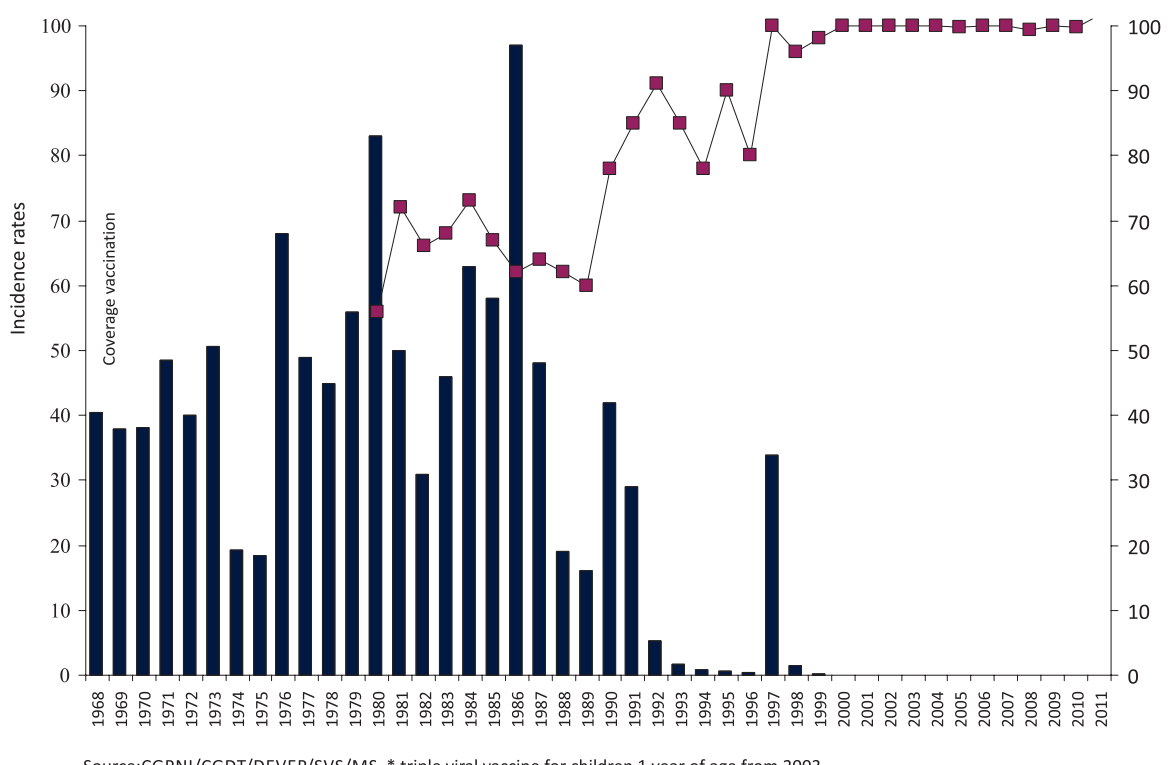

Fig 2 - Incidence rates of measles and vaccination coverage with monovalent measles and triple viral*, Brazil, from 1968 to 2011.

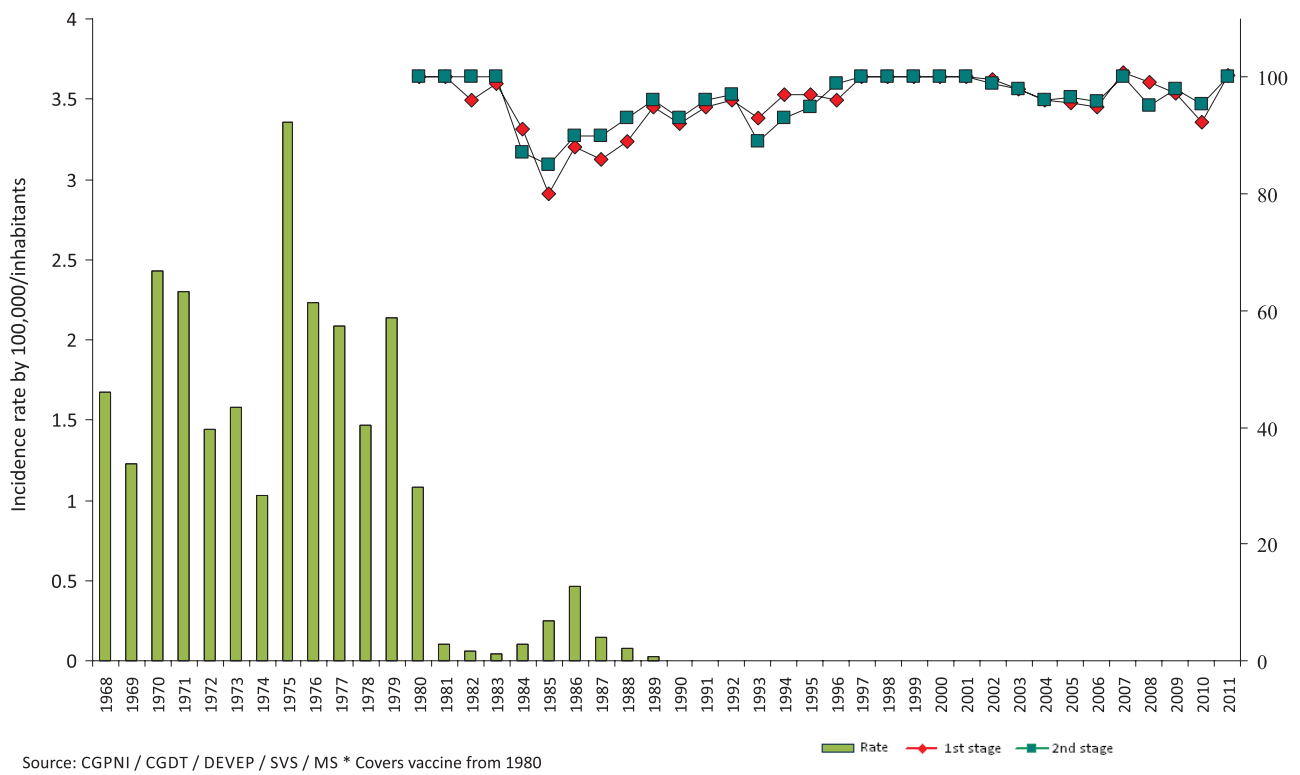

Fig. 3 - Incidence of poliomyelitis and vaccine coverage in vaccination campaigns with OPV in children under 5 years of age*, Brazil, from 1968 to 2011.

Rio de Janeiro and Rio Grande do Norte, reaching a vaccination coverage of $96.79 \%$ of the target population in about 20 weeks of vaccination.

Considered the largest immunization campaign in the world, due to the large number of people to be vaccinated, the immunization campaign against rubella was exceeded by the number of doses applied by the national immunization campaign to influenza A (H1N1) 2009 held in 2010. This had as eligible groups health workers; patients with chronic illnesses, children between six months and under two years old; indigenous; pregnant women and young adults aged 20 to 39 years. 89.5 million doses of vaccines were reported to be applied within three months. Vaccination coverage with a established target of $80 \%$ for each target group was overcome in most of them, except for pregnant women (77.1\%) and in adults aged 30 to 39 years $(75.3 \%)$, highlighting that this latter group was only included in the final phase of the campaign, which can explain the less favorable results.

Considering the heterogeneity in the vaccination results when the situation in the context of cities for any vaccine and target population is analyzed, overall results demonstrate the operational capacity of PNI in the different SUS management levels. The implementation of plans for control and elimination of diseases, the strategies adopted for immunization, emphasizing the multivaccination from 1990 on the national days for immunization against polio, contributed to 


\begin{tabular}{|c|c|c|c|c|c|c|c|c|}
\hline \multirow[b]{2}{*}{ Year } & \multicolumn{8}{|c|}{ Type of vaccines } \\
\hline & BCG & Нер В & $\begin{array}{l}\text { Polio } \\
\text { (OPV) }\end{array}$ & $\begin{array}{l}\text { DTP+Hib } \\
\text { (Tetra) }\end{array}$ & $\begin{array}{c}\text { Oral } \\
\text { Human } \\
\text { Rotavirus } \\
\text { (VORH)** }\end{array}$ & $\begin{array}{l}\text { Pneumo } 10 \\
\text { valente* }\end{array}$ & $\begin{array}{c}\text { Meningo } \\
\text { Conjugated C* }\end{array}$ & $\begin{array}{l}\text { Triple viral } \\
(\text { (MMR)** }\end{array}$ \\
\hline 2001 & 112.6 & 91.9 & 102.8 & 97.5 & & & & 88.4 \\
\hline 2002 & 110.6 & 91.5 & 100.0 & 98.9 & & & & 97.4 \\
\hline 2003 & 108.4 & 91.9 & 96.2 & 97.4 & & & & 113.0 \\
\hline 2004 & 106.4 & 90.4 & 98.1 & 96.2 & & & & 105.2 \\
\hline 2005 & 106.5 & 91.6 & 98.3 & 95.4 & & & & 99.7 \\
\hline 2006 & 109.0 & 96.7 & 98.6 & 99.8 & & & & 102.2 \\
\hline 2007 & 106.8 & 95.1 & 101.5 & 98.3 & 79.8 & & & 104.8 \\
\hline 2008 & 109.4 & 96.6 & 100.7 & 98.7 & 81.1 & & & 101.3 \\
\hline 2009 & 106.9 & 98.5 & 101.9 & 99.9 & 85.9 & & & 101.8 \\
\hline 2010 & 106.5 & 95.6 & 99.2 & 97.8 & 83.0 & & & 99.1 \\
\hline 2011 & 107.7 & 97.6 & 101.1 & 99.5 & 86.9 & 81.4 & 105.5 & 102.2 \\
\hline
\end{tabular}

Fig. 4 - Vaccination coverage (\%) by type of vaccination in the child's, Brazil, 2001 to 2011.

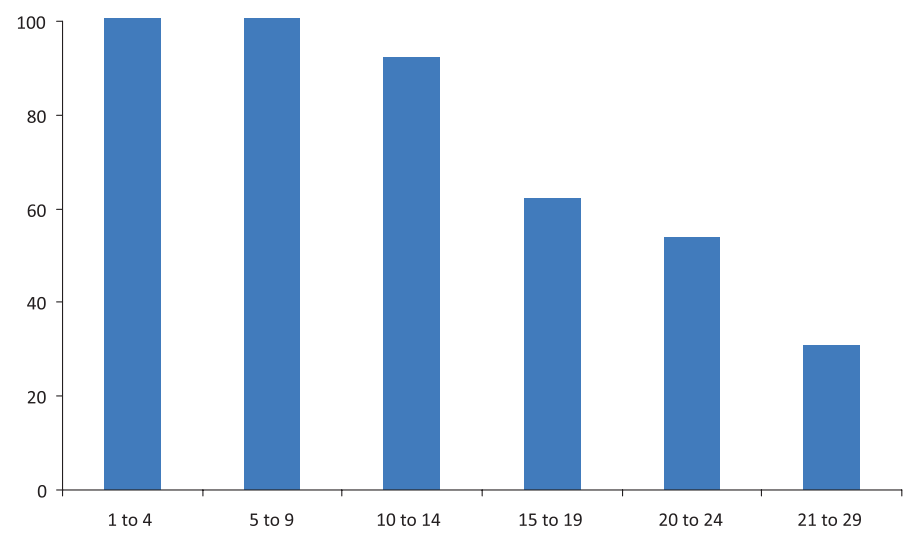

Source:CGPNI/DEVEP/SVS/MS

Fig. 5 - Vaccination accumulated hepatitis B vaccine by age group, Brazil, from 1994 to 2011.

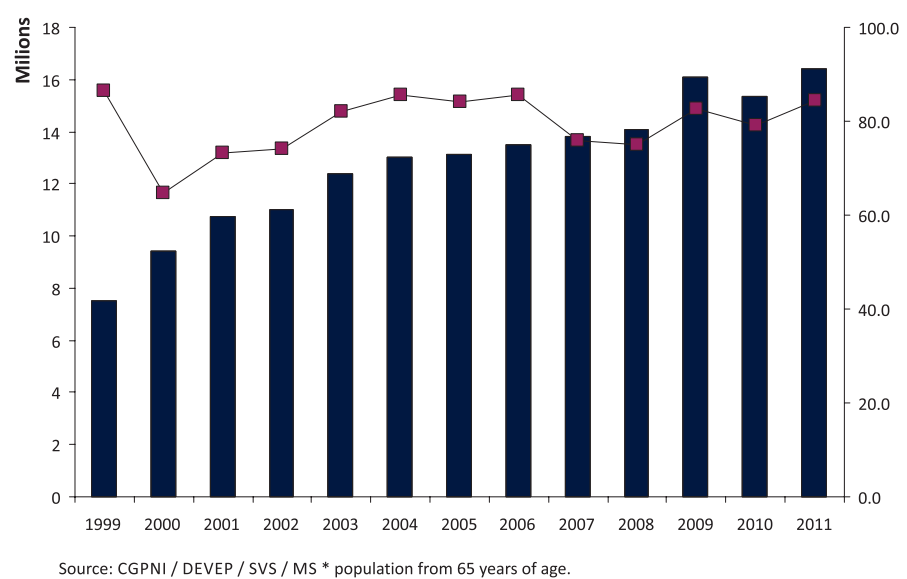

Fig. 6 - Doses administered and vaccine coverage of influenza vaccine in elderly people, Brazil 1999 to 2011*.

greater compliance of the population. Added to these, the expansion of health services and the decentralization process, factors that directly or indirectly contribute to the improvement of the access, increasing
$\mathrm{VC}$ and promoting impact on disease subjected to surveillance in the country.

The implementation of new vaccines is a goal of PNI and important advances have occurred in the area of immunization in the country over the past two centuries. More vaccines and target groups were gradually included in the immunization program in Brazil. When establishing as one of the criteria for vaccine deployment the safety and effectiveness of the product, PNI has in its favor the credibility in the Program and recognition of the population that the vaccine is the primary measure to control a significant proportion of diseases.

The results observed from vaccination coverage in different strategies testify in favor to gradual compliance of population to vaccination whether routine immunization or in immunization campaigns, and have as outcome preventable diseases eradicated, and or under control with incalculable benefits to the population. However, the maintenance of the current status and progress to obtain new achievements depend on obtaining and maintaining high and homogeneous vaccination coverage and a surveillance system for adverse events sensitive to detect, investigate and intervene in a timely manner. These, among others, are fundamental in order to maintain the credibility and success of PNI.

\section{PHARMACOVIGILANCE}

Vaccination programs have been one of the safest and most costeffective measures in public health. There is no other procedure that produces such excellent results in reducing morbidity and mortality and also provides so many possibilities, such as the eradication of immunepreventable diseases, that led to eradication of smallpox in the world, the elimination of poliomyelitis in the Americas since 1994, the elimination of measles in Brazil (last case reported in 2000), rubella elimination and control of congenital rubella syndrome in Brazil.

The vaccines are given to large groups of healthy individuals, and therefore, safety and quality are of great importance. Current vaccines are very safe, because they meet strict quality parameters from production to their application. In general, they are among the safest pharmaceutical products for human use, providing broad benefits to public health of a country.

Unfortunately, like all medical interventions, the immunization procedures are not completely safe. With the increase in vaccination coverage, both in developed and developing countries, the reduction of immunepreventable diseases occurs; however, there is a growing concern about the safety of vaccines, i.e., with the increased number of adverse events following immunization (AEFI).

Immunization programs have the responsibility to address the public concern related to vaccines by providing workers with updated information on safe immunization practices.

Safe vaccination is a priority component of immunization programs that seeks to ensure the use of quality vaccines, and this quality control in Brazil is carried out by the National Institute for Quality Control in Health, Oswaldo Cruz Foundation (Instituto Nacional de Controle de Qualidade em Saúde da Fundação Oswaldo Cruz,(INCQS/FIOCRUZ)); the shipping and storage with appropriate packaging, the use of safe 
injection practices from appropriate administration to final disposal, the performance of surveillance of adverse events following immunization with early and efficient investigations and strengthening alliances with the media according to the perception of the population using clear messages to the public about the strategies, priorities and safety of vaccination.

An adverse event following immunization (AEFI) is any health problem temporally related to vaccination, caused or not by the vaccine administered. Such events may be related to the composition of the vaccine, the individuals vaccinated, the technique used for administration (programming errors), or overlapping with other health problems. Given the nature and characteristics of immunebiologicals, as well as the knowledge already available from experience, events can be expected: fever, local pain, myalgia, headache, hyporesponsive hypotonic episode, among others, or unexpected, which are those not previously identified (e.g.: new vaccines) or resulted from problems related to production (inappropriate endotoxin content in certain vaccines causing febrile reactions similar to sepsis, contamination of batches causing abscesses) ${ }^{9}$.

For best results all the people who participate in safe immunization activities should exercise their activities in an integrated manner: National Regulatory Agency - Anvisa, epidemiological surveillance, national laboratory for quality control, anatomical pathology laboratories, professional organizations, communicators, vaccine producers, World Health Organization/Pan American Health Organization and cooperating bodies $^{10}$.

Since 1991 the World Health Organization (WHO) recommends surveillance of adverse events following immunization. Since 2000, the Brazilian Ministry of Health implemented the information system for surveillance of adverse events following immunization (SI-EAPV) and because of the importance, by the ordinance of the Secretariat of Health Surveillance, this was introduced as an injury of compulsory reporting (Pt SVS/MS n 33 of 25/Jul/2005), and according to Resolution RDC Anvisa $\mathrm{n}^{\circ} 4$ of $10 / \mathrm{Feb} / 2009$, which sets forth the standards of pharmacovigilance to record holders of medicinal products for human use, who must notify, as soon as possible, any adverse event ocurring in the national territory, setting the maximum period of seven days from the date of knowledge of the adverse event information.

The objectives of AEFI surveillance are: to regulate the recognition and procedure in the case of adverse events following immunization (AEFI), to identify serious adverse events, new and/or rare, to establish or rule out a causal relationship with the vaccine, to identify more reactional batches, to detect, correct and prevent programmatic or operational errors, to update contraindications and analysis of risks and benefits, to estimate incidence rates and generate new hypotheses.

All public and private health services offering vaccine rooms, basic health units, emergency care and hospitals are responsible for notifying AEFI. Notification is a mechanism that helps maintain an active monitoring system and a status of permanent alertness of the health worker for the detection of $\mathrm{AEFI}^{10}$. Also highlighted is that in any epidemiological situation, serious AEFI should be reported within 24 hours from the occurrence, from local to national level following the flowchart determined by the National Immunization Program of the Ministry of Health.
Every event in which the patient, parents or guardians, the public, health professionals consider related to the administration of a vaccine should be investigated in the place of occurrence. If the period of onset and the symptoms/signs indicate the possibility that this event has a relationship with the vaccine, further investigation should be immediately initiated with assistance of state and national levels. The purpose of the investigation is to confirm or discard the event notified, to determine whether there are other possible causes, to check if this is an isolated event and to report to the parties involved.

The early, honest and efficient communication of the results of one investigation assure the integrity of immunization programs ${ }^{11}$.

International experience shows that the supply and use of safe and quality vaccines is a prerequisite for the high compliance of the population, as well as health workers, to the immunization programs. However, it is expected that a healthy and democratic debate about risks and benefits of immunization is ruled by the need for caution and great responsibility on issues of such relevance to the health of Brazilian population $^{12}$.

\section{REFERENCES}

1. Brasil. Ministério da Saúde. Secretaria de Vigilância em Saúde. PNI/30 Anos. Cap. 2. Pela eficácia das vacinas. In: Datas e fatos históricos das imunizações e doenças imunopreveníveis no Brasil e no mundo. Brasília: SVS; 2003. p. 57-107.

2. Viveiro A. A revolta da vacina. Rev Eletrônica Ciênc. [cited: 2011 October 4] Available from: http://cdcc.usp.br/ciencia/artigos/art_49/editorial_ed49.html.

3. Uma epidemia sob censura. [Cited: Oct 4 2011]. Available from: http://www.ccs. saude.gov.br/revolta/pdf/M9.pdf.

4. Barata RC. Saúde e direito a informação. Cad Saúde Pública. 1990;6:385-99. Available from: http://www.scielo.br/pdf/csp/v6n4/v6n4a03.pdf.

5. Temporão JG. O Programa Nacional de Imunizações (PNI): origens e desenvolvimento. Hist Cienc Saude Manguinhos. 2003;10(Suppl 2):601-17. Available fromhttp://www. scielo.br/scielo.php.

6. A produção e o desenvolvimento de vacinas no Brasil. [cited: 2011 October 4] Available from: http://www.scielo.br/pdf/hcsm/v3n1/v3n1a08.pdf.

7. Campos ALV, Nascimento DR, Maranhão E. A história da poliomielite no Brasil e seu controle por imunização. Hist Ciênc Saúde Manguinhos. 2003;10(Suppl 2):573-600.

8. Brasil. Ministério da Saúde. Secretaria de Vigilância em Saúde. Relatório da verificação dos critérios de eliminação da transmissão dos vírus endêmicos do sarampo e rubéola e da síndrome da rubéola congênita (SRC) no Brasil. Brasília: Secretaria de Vigilância em Saúde; 2003.

9. Brasil. Ministérioda Saúde. Manual de vigilância epidemiológica de eventos adversos pós-vacinação. $2^{\mathrm{a}}$ ed. Brasília: Ministério da Saúde; 2008.

10. Vacunación segura: módulos de capacitación. Washington: Organización Panamericana de la Salud/Organización Mundial de la Salud; 2007.

11. Waldman EA, Luhm KR, Monteiro AS, Freitas FR. Vigilância de eventos adversos pós-vacinação e segurança de programas de imunização. Rev Saude Publica 2011;45:173-84.

12. Martins RM, Maia MLS. Eventos adversos pós-vacinais e resposta social. Hist Ciênc Saúde Manguinhos. 2003;10(Suppl 2):807-25. 